\title{
Fostering critical thinking and collaborative learning skills among medical students through a research protocol writing activity in the curriculum
}

\author{
Soumendra Sahoo ${ }^{1}$ and Ciraj Ali Mohammed ${ }^{2}$ \\ ${ }^{1}$ Department of Ophthalmology, Melaka Manipal Medical College (Melaka Campus), Bukit Baru, Malaysia and \\ ${ }^{2}$ Department of Microbiology, Melaka Manipal Medical College (Manipal Campus), Manipal Academy of Higher \\ Education, Manipal, India
}

Purpose: This intervention was aimed to analyse the effect of academic writing and journal critiquing as educational approaches in improving critical thinking and collaborative learning among undergraduate medical students.

Methods: A research proposal writing format was created for the 4th year medical students of Melaka Manipal Medical College, Malaysia during their ophthalmology clinical postings. The students worked in small groups and developed research protocols through an evidence based approach. This was followed by writing reflective summaries in academic portfolios about the activity undertaken. A mixed methods study was designed to explore the possible role of collaborative research proposal writing in enhancing critical thinking and collaborative learning.

Results: Analysis of reflections submitted by 188 medical students after the intervention indicate that majority of them found an improvement in their skills of critical thinking and collaborative learning as a result of research protocol writing. All participants agreed that the model helped in applying concepts to new situations in the form of designing their own study, which reflected in enhanced higher order cognitive skills.

Conclusion: This study shows that the introduction of a structured module in the core medical curriculum that focuses on research writing skills embedded with collaborative and reflective practices can enhance collaborative learning, critical thinking, and reasoning among medical students.

Key Words: Research design, Thinking, Learning, Research

\section{Introduction}

Critical thinking is a higher order skill which helps in evaluating the pros or cons by rational reasoning of evidence. The current approaches in medical education focuses more on developing critical thinking skills among the learners [1]. By doing so, future health care professionals are able to evaluate the argument of others and themselves, often helping them in resolving professional dilemmas. Tittle [2] in 2011 linked critical thinking to qualities such as effective questioning, being empathetic, honest, analytical, and objective. It is an accepted view that critical thinking notions and instruments are fundamental in organised instructions.

In higher education, specifically in medical education,
Received: December 27, 2017 • Revised: February 26, 2018 • Accepted: March 22, 2018 Corresponding Author: Ciraj Ali Mohammed (https://orcid.org/0000-0001-7849-7692) Department of Microbiology, Melaka Manipal Medical College (Manipal Campus), Manipal Academy of Higher Education, Karnataka State, Manipal, Karnataka 576104, India Tel: +91.820.2573782 Fax: +91.820.2571905 email: ciraj.am@manipal.edu
Korean J Med Educ 2018 Jun; 30(2): 109-118. https://doi.org/10.3946/kjme.2018.86 eISSN: 2005-7288

(C) The Korean Society of Medical Education. All rights reserved. This is an open-access article distributed under the terms of the Creative Commons Attribution Non-Commercial License (http:// creativecommons.org/licenses/by-nc/3.0/), which permits unrestricted non-commercial use, distribution, and reproduction in any medium, provided the original work is properly cited. 
educators continuously stress to apply critical thinking in all facets of academic study, be it to select information, to read, to write, to speak, or even to listen. Critically reading and evaluating information are seen by some as the most important skills to develop, as they have wide applicability in other aspects of cognition. In health professions courses, critical thinking remains a vital skill to hone, which would help the learner to perform without flaws in their future workplace scenarios. This approach enables the learner to make an evaluation of current knowledge along with fostering the creation of new knowledge. It is not surprising to note the majority of health science courses acknowledge the magnitude of importance for learners to establish critical thinking skills. In order to deliver effective health care while maintaining safety for healthcare seekers, healthcare workers are required to develop effective clinical reasoning and acumen [3]. For the same reasons critical thinking is considered important in the practice of medicine and the health sciences, in health science research and in philosophy of medicine itself. Thinking critically can provide broader perspectives, creative solutions, multiple pathways and scope for more selfregulation [4]. Research says that critical thinking can be taught, however it should be done in such a way that learners are engaged actively with teachers who transform themselves as facilitators [5].

Critical thinking has been viewed as more than a unique collection of cognitive skills. Authors have described critical thinking to encompass the ability to comprehend the essence of deriving conclusions and to consider the justification behind the evidence [6-10]. They also consider critical thinking as a fundamental requirement for application to the most complex reallife scenarios and for active participation in social circles.

One institutional study reveals how writing exercises and group discussions can facilitate for the development of critical thinking [11]. Critical appraisal teaches objectivity, reflection and logic that encourages critical thinking in both practice and theory. Students can even develop transferable thinking skills through focused critical appraisal activities leading to enterprising, reflective judgement which allow for comprehension, analysis, appraisal, and deduction [12]. The approach also fosters explanation of key factors which influence judgement. Tittle has postulated that the steps of critical thinking follow this order: observing, analysing, evaluating, contextualising, questioning, and finally reflecting (Fig. 1). As we notice in this hierarchy, an exercise of higher order cognitive skills as described by Bloom et al. [13] is evident throughout the process. Hence, various tools have been proposed for teaching critical thinking skills, these include but are not limited to; written assignments, problem based learning, analysing case studies, work-integrated learning on placement, and the use of simulations [14].

Academic writing has been recognised to help learners develop critical thinking skills as the complexity of writing skills necessary increases from undergraduate to post-graduate level [15,16]. Scientific writing can encourage the development of self-expression, organisational skills, and both descriptive and observational

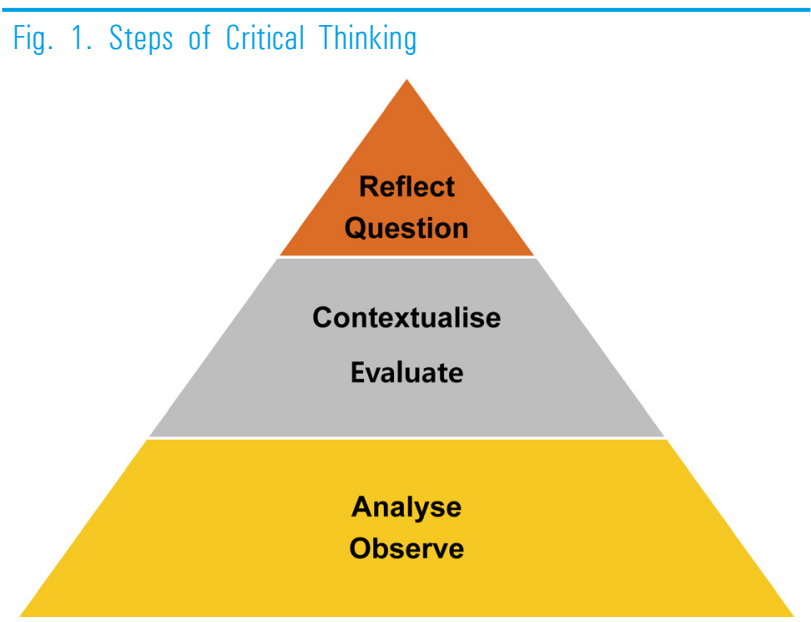


skills [17]. These soft skills are essential for practice of medicine. Academic writing is considered a necessary skill for communicating novel research and to produce evidence [18]. Students interacting with academic literature will allow students to further develop their critical thinking skills and will go a long way for the development of a scientifically-literate community [19]. Researchers have suggested that scientific writing needs to be taught, looking into the enhancement of critical thinking skills among university students [20].

It is established that the effectiveness of written communication positively correlates with the quality of care provided and patient safety [21]. There is also an increasing emphasis on academics to publish research which highlights the importance of providing opportunities to hone the skills in academic writing during their training phase itself.

Considering the aforementioned background, we designed an educational intervention that was aimed in developing research proposals by medical students to present and justify the need to study a research problem and to suggest practical ways in which this research must be organised. This approach was developed as an assignment for the learners to improve their critical thinking by exercising justification and reasoning in their protocols. We have also attempted to analyse the undergraduate medical students' perceptions on how the research protocol writing in small groups have contributed towards enhancing their critical thinking and collaborative learning skills.

\section{Methods}

\section{Context and participants}

This study was conducted in the Department of
Ophthalmology, Melaka Manipal Medical College (Melaka Campus), Malaysia from July to December 2015. The college offers a Bachelor of Medicine and Bachelor of Surgery program that is of 5 years duration. The institution follows a hybrid curriculum with majority of subjects taught discipline wise and integration imparted through concurrent problem-based learning sessions. Of the 10 semesters that span over a period of 5 years, the first 4 semesters deal with pre and para-clinical subjects which is followed by 6 semesters of clinical training. The lecture topics of ophthalmology are covered during 6th and 7th semester with clinical postings scheduled during the 8th and 9th semester. The institution has a multi ethnic student population mostly from within Malaysia and a few international students from select countries across the globe.

A total of 188 fourth year medical students during their clinical posting in ophthalmology were recruited for this study after obtaining informed consent. They were further divided into small groups using random allocation (by drawing lots) to ensure that the groups were heterogeneous. A standard protocol template developed by the department known as 'Proposal Wizard' was used for the participants. The proposal wizard had five headings: title, rationale, objectives, study design, and references.

An orientation session conducted during the first day of the 4-week clinical posting briefed the participants about using various electronic search engines to retrieve published articles. Two hypothetical research questions were framed for this study considering the prevalence of ophthalmic diseases and their social relevance in this South East Asian zone. The questions used were: "Can we prevent cataract?" and "Can we prevent diabetic retinopathy?"

The participants were instructed to write a proposal for conducting a clinical study in this zonal context to 
answer the aforementioned research questions. They were asked to focus on three questions: (1) why was this study important?; (2) what will you do to address this problem/need/opportunity?; and (3) who or what will change as a result of your study?

Participants were instructed to perform activities such as literature search using various search engines, developing research questions in the local context and retrieval of at least five references for protocol writing. While writing the background, the participants were cautioned not to make this an exhaustive literature review. We advised that besides providing a clear idea of what the research question was and by understanding its originality and relevance, they had to state clearly as to how this research would help in filling the gaps in the existing literature.

This was followed by actual protocol writing in the assigned groups using a given template, "Proposal Wizard”. Subsequent to the study, the participants were asked to provide an individual reflection on the activity in their respective portfolios. In the reflective summaries, they were encouraged to depict their responses to experiences, opinions, events, and responses to thoughts and feelings. They were also asked to reflect on the learning process that happened as a result of this intervention and ways of creating meaningful experiences from the learning process.

\section{Study design}

A mixed methods approach was adopted to analyse the effectiveness of this intervention. Qualitative method was used to explore students' perceptions of the enhancement of critical thinking skill through research protocol writing in small groups. A quantitative approach was used to identify the components that had the strongest impact to strengthen the qualitative data.

\section{Data analysis}

Qualitative analyses of the reflections were done by coding and identifying categories and themes. Words with similar meanings were grouped into emergent major codes. The major codes were further classified into categories. These categorizations subsequently led to the emergence of major themes [22].

A survey questionnaire was used to perform the quantitative analysis of the themes that emerged during qualitative analysis. This questionnaire where the statements were measured in Likert scale was given to participants in order to understand the effect of research protocol writing exercise in enhancing critical thinking and collaborative learning skills. This study was approved by the Institutional Ethics Committee of Melaka Manipal Medical College (Melaka Campus), Malaysia (approval no., MMMC/REC/03/2016).

\section{Results}

The demographic profile of the participants is given in Table 1. They belonged to the age group of 21-23 years. The students who were motivated by active participation in small groups during this activity opined that:

\begin{tabular}{|c|c|}
\hline Gender and ethnicity & Total no. $|\%|$ \\
\hline Male & 83 (44.14) \\
\hline Malay & $20(10.63)$ \\
\hline Chinese & 28 (14.89) \\
\hline Indian & $33(17.55)$ \\
\hline Others & $2(1.06)$ \\
\hline Female & 105 (55.86) \\
\hline Malay & $39(20.74)$ \\
\hline Chinese & $33(17.55)$ \\
\hline Indian & $30(15.95)$ \\
\hline Others & $3(1.59)$ \\
\hline
\end{tabular}


"This was an interesting and informative assignment..."

"This assignment made learning fun, easy, and inspiring..." "We had lots of fun while working on the given assignment $\cdots "$

Students also expressed that the protocol writing activity honed their skills in team work and collaborative learning.

"Throughout the process I learnt team work..."

"It gave me opportunity to mingle with my friends in developing effective team building where equal learning took place..."

"I could learn better by sharing my thoughts in a group as well as looking into the discussion of my peers in group..."

The activity assigned was recognised by many as a process that helped in fostering the skills of critical inquiry and active learning.

"This gave me opportunity to reflect, research, raise questions, and present in an active manner..."

"The exercise of research proposal writing helped me to synthesise facts and organise information to create a new thinking..."

"It encouraged my critical thinking about my own and other's actions...”

"By doing inquiry on research topics and developing a proposal I could engage myself in deeper thinking and deeper learning..."

The students also recognised the complexity of the task and process.

"I felt it was a process of considering a topic or problem from multiple perspectives...

"It was not easy to pick key elements from research done elsewhere that could be employed in our own context of conducting research...”

"The group exercise gave me scope to understand the complexities involved in critiquing literature, more so for conducting a research..$”$

There were a few concerns shared by some participants especially about resolving conflicts within the group and meeting the deadline in completing the assignment.

"Sometimes we faced difficulty in resolving multiple opinions in group...”

"I hate when my idea is not given credit within the group..."

"Few of my group members were dominant which sometimes prevented myself expressing some of my critical observations..."

"Time constraint was the issue in finishing this assignment $\cdots ”$

When relating the skills of critical thinking to academic writing the participants mentioned that:

"It is impossible to write a good proposal without employing critical thinking..."

"I am sure; I could improve my critical thinking through this research proposal writing...”

"We should be stressed on critical thinking skill as a core component of our curriculum...”

Some of the key words that emerged from the qualitative data identified the assignment as interesting, inspiring, providing exposure, communication skills, team work, and time constraints. Words with similar meanings were grouped into emergent major codes such as memorising, analysing basic elements, synthesising, organising ideas, and being inquisitive. The major codes were further classified into two categories which were 
cognitive skill enhancement and active collaborative learning. These categorizations subsequently led to the emergence of major themes such as enhancing teamwork and enhancement of critical thinking skill. Thematic

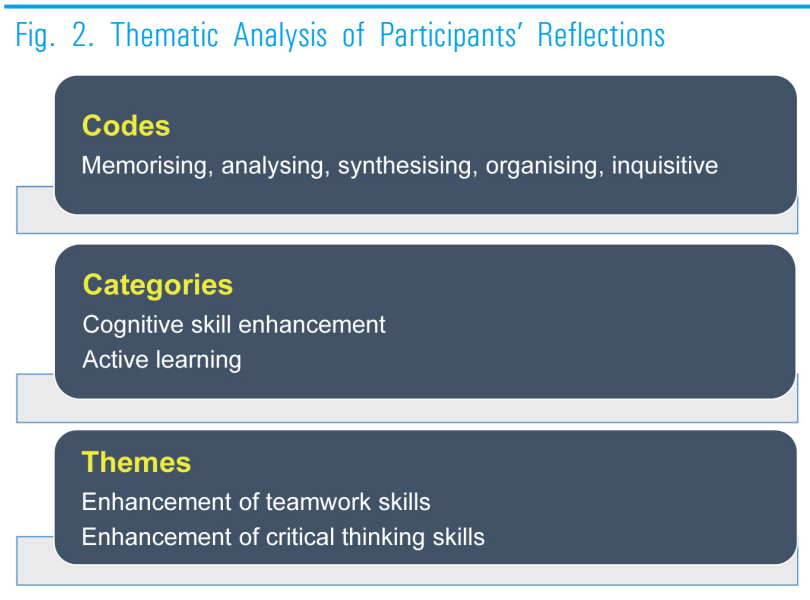

analyses of student reflections are depicted in Fig. 2.

The methodologies adopted by the students are highlighted as exemplars in Table 2. This provides insight to the thought process of learners in writing the study design for intended purposes.

The survey questionnaire report is depicted in Table 3 where the responses are shown as average of Likert scales used (1-5: 1 as strongly disagree and 5 as strongly agree).

\section{Discussion}

The development of students' critical thinking abilities remain a major challenge faced by today's health educators. Ongoing research in this field still strives to

\begin{tabular}{|c|c|c|}
\hline $\begin{array}{c}\text { Type of methodologies } \\
\text { planned }\end{array}$ & Exemplar (E) & $\%$ \\
\hline $\begin{array}{l}\text { Methodology not } \\
\text { described }\end{array}$ & $\begin{array}{l}\text { E1: A longitudinal study is to be conducted for } 5 \text { years. } \\
\text { E2: This study will be conducted for } 1 \text { year to determine which of the following methods: retinal } \\
\text { photography or ophthalmoscopy is more effective in screening diabetic retinopathy. } \\
\text { E3: We would like to study the patients visiting retinopathy screening clinic for a period of } 2 \text { years. }\end{array}$ & 9.6 \\
\hline $\begin{array}{l}\text { Observational } \\
\text { methodology }\end{array}$ & $\begin{array}{l}\text { E4: This prospective cohort study on diabetic retinopathy prevention will target on looking into } \\
\text { the effectiveness of strict glycemic control in reducing \& preventing the risk of diabetic } \\
\text { retinopathy. This study is best studied using prospective cohort as we will be obtaining information } \\
\text { from patients who are under exposed group. } \\
\text { E5: Our study will be an observational single centre case control study. } \\
\text { E6: A cross sectional study is to be conducted to study the exposure of ultraviolet on the development } \\
\text { of age-related cataract. } \\
\text { E7: The present study is a } 5 \text { years prospective cohort study. Ethical committee clearance will be } \\
\text { taken. }\end{array}$ & 50.0 \\
\hline $\begin{array}{l}\text { Intervention } \\
\text { methodology }\end{array}$ & $\begin{array}{l}\text { E8: The randomised controlled experimental study is to be conducted. } \\
\text { E9: We plan to conduct a double blinded randomized controlled trial to study the effect of ruboxistaurin } \\
\text { (a protein kinase C inhibitor) in the prevention of diabetic retinopathy. } \\
\text { E10: A case-control study to investigate the association of curcumin in prevention of diabetic } \\
\text { retinopathy in Malaysian (Melakal population. } \\
\text { E11: This will be an intervention study, of a randomized controlled trial whereby the study of } \\
\text { anti-oxidant supplementation and prevention of age related cataract in Melaka General Hospital. } \\
\text { E12: Based on a study done by researchers from Diabetic Retinopathy Clinical Research Network } \\
\text { which was funded by the National Eye Institute of the United States, we will conduct an } \\
\text { interventional study involving a target sample size of } 300 \text { patients registered in Klinik Kesihatan } \\
\text { Peringgit for diabetic follow-up. } \\
\text { E13: The study design we would choose is randomized triple blind controlled trial to investigate } \\
\text { the efficacy of antioxidant vitamins and zinc in cataract prevention. }\end{array}$ & 40.4 \\
\hline
\end{tabular}


Table 3. Survey Scores from Student Response Surveys $(N=188)$

\begin{tabular}{|c|c|c|c|}
\hline Statements & $\begin{array}{l}\text { Average score } \pm \text { standard } \\
\text { deviation }\end{array}$ & Max/min score & $\begin{array}{c}\% \text { of strongly agree } \\
\text { or agree }\end{array}$ \\
\hline $\begin{array}{l}\text { This approach helped me in memorizing facts, ideas or methods } \\
\text { from article readings. }\end{array}$ & $4.7 \pm 0.3$ & $5 / 4$ & 100.0 \\
\hline $\begin{array}{l}\text { The approach helped in analysing the basic elements of an idea, } \\
\text { experience or theory, such as examining a particular studyin depth } \\
\text { and considering its components. }\end{array}$ & $4.6 \pm 0.4$ & $5 / 3$ & 92.3 \\
\hline $\begin{array}{l}\text { This method aided in synthesising and organising ideas, information } \\
\text { into new and more complex interpretations. }\end{array}$ & $4.8 \pm 0.4$ & $5 / 4$ & 100.0 \\
\hline $\begin{array}{l}\text { The methodology adopted assisted in making judgements about } \\
\text { the value of information, arguments or methods (such as } \\
\text { examining how others gather and interpret data) and assessing } \\
\text { the conclusion along with application at one's own setting. }\end{array}$ & $4.7 \pm 0.4$ & $5 / 3$ & 98.0 \\
\hline $\begin{array}{l}\text { This model helped in applying theories or concepts to practical } \\
\text { problems or in new situations in the form of designing own study. }\end{array}$ & $4.8 \pm 0.5$ & $5 / 4$ & 100.0 \\
\hline This approach helped in enhancing my critical thinking skills & $4.7 \pm 0.4$ & $5 / 3$ & 92.3 \\
\hline This method enhanced my team working skills. & $4.8 \pm 0.5$ & $5 / 3$ & 98.0 \\
\hline
\end{tabular}

identify appropriate context to promote the development of critical thinking. Our study was designed to endorse critical thinking among final year medical students to work collaboratively and develop a research proposal using an evidence based approach. The general expectation during an academic writing assignment is that students are encouraged to think critically. This was observed while analysing the exemplars on methodologies planned by the participants.

Writing assignments provide students the opportunities to reflect in addition to fostering communicative skills and critical thinking [22]. This supports our idea of engaging students in reflective writing that followed collaborative exercises on proposal writing in order to foster critical thinking skills.

Research points out that the reflective learning process enables learners to alter their outlook at six unique stages in their decision-making process. These steps are: introspection, concept attainment, self-attribution, problem solving, action planning, and reorganization [23]. By engaging with foresight and planning, reflective writing can be a productive strategy for facilitating students' skills of critical thinking and reasoning.
Critical thinking can improve proficiency in learning the relevant course content. A study done in Malaysia provides evidence on the importance of improving the undergraduates' English language proficiency by positively relating it to critical thinking ability [24]. This justifies our approach of utilising a strategy like proposal writing for refining such skills. However, there are number of issues with the theory and methodology of the expressive writing model as articulated by some workers [25]. These workers argue for a more prudent and critical approach rather than the experimental and quantitative approach which has predominated expressive writing. They also point out the wide array of manners in which creative writing has been utilized in healthcare environments to support their arguments [26].

Establishing and maintaining relationships are considered as crucial components for success in the research process [27]. Research teams working in collaboration have found that prioritising effective communication and writing serves to develop knowledge, which was also found from the self-reflection of the study participants in this study. A multi centric study, which attempted to encourage critical appraisal of education reports, 
discovered enhanced interpretation, better judging abilities, and skill in formulating proposals for critical reading [28].

The opportunity given to the members to experience writing collaboratively not only encourages active learning but also facilitates for experiencing working in a team [29]. This was evident in our study where most of the participants agreed upon enhancement of their skills of functioning within a team which can be considered as a major outcome of this intervention. While working in small groups, few participants expressed their concern especially regarding the resolution of certain conflicts that arose within the team. However, when they realized similar difficulties are shared by others, they eventually felt less isolated in the process. Similar effects are documented in another study as well [30].

Some researchers lament that in spite of the hefty importance given for publication, there is limited research and support for teachers attempting to improve the quality of their academic writing [31]. This finding augments the need for inculcating skills of academic writing in medical schools right from the formative years itself. The interests generated among our participants provide a ray of hope as similar interventions can help in boosting learner motivation leading to amplification of their skills in academic writing. We also identified that engaging students in the design of scientific research protocol writing allowed teachers to detect different ways in which students understand scientific practices, which has been depicted in Table 2. The findings match with a study done by Domènech and Márquez [32] to a large extent.

In this study we did not measure critical thinking using any standardised scale which may be considered as a limitation. Future studies incorporating such measures can be organised in the same setting for performing an in-depth analysis of this topic. Based on the results of this study, we recommend structured modules in the core medical curriculum that focus on research writing skills with reflective practices embedded in a collaborative learning format for fostering the skills of critical thinking and collaborative learning among undergraduate medical students.

In conclusion, majority of students who participated in this study agreed that research protocol writing in small groups using an evidence based approach enhanced their critical thinking and collaborative learning skills. The responses in favour of this intervention cited the approach as "interesting, inspiring, good exposure, and enhancing the skills of effective communication and teamwork." Time constraints and issues associated with resolving conflicts within the team were identified as major hindering factors.

\section{ORCID:}

Soumendra Sahoo: https://orcid.org/0000-0003-0356-0874; Ciraj Ali Mohammed: https://orcid.org/0000-0001-7849-76922 Acknowledgements: We would like to thank Prof. Datuk, Dr. Abdul Razzak, Pro-Vice-Chancellor Manipal University, Prof. Jaspal Singh Sahota, Chief Executive, Melaka-Manipal Medical College and Dean (FOM) MMMC, Malaysia, and Prof. Adinegara Lufti Abas, Deputy Dean Melaka-Manipal Medical College, Malaysia for their support, constructive comments, and encouragement in executing this project.

Funding: None.

Conflicts of interest: No potential conflict of interest relevant to this article was reported.

Author contributions: Conception or design of the work: SS, CAM; data collection: SS; data analysis and interpretation: CAM; drafting the article: SS; critical revision of the article: CAM; and final approval of the version to be published: SS, CAM. 


\section{References}

1. Bailin S. Critical thinking and science education. Sci Educ. 2002;11(4):361-375.

2. Tittle P. Critical thinking: an appeal to reason. London, UK: Routledge; 2011.

3. Black B, Thompson A. An A to $\mathrm{Z}$ of critical thinking. London, UK: Continuum; 2012.

4. Facione NA, Facione PA. Critical thinking and clinical judgment. In: Facione NC, Facione PA, eds. Critical Thinking and Clinical Reasoning in the Health Sciences: An International Multidisciplinary Teaching Anthology. Millbrae, USA: The California Academic Press; 2008.

5. Facione NC, Facione PA, Sanchez CA. Critical thinking disposition as a measure of competent clinical judgment: the development of the California Critical Thinking Disposition Inventory. J Nurs Educ. 1994;33(8):345350.

6. Watson G, Glaser EM. Watson-Glaser critical thinking appraisal. San Antonio, USA: The Psychological Corporation; 1980.

7. McPeck JE. Critical thinking and education. New York, USA: St. Martin's Press; 1981.

8. Paul R. Teaching critical thinking in the 'strong' sense: a focus on self-deception, world views, and a dialectical mode of analysis. Informal Log Newl. 1982;4(2):2-7.

9. Paul R. An agenda item for the informal logic/critical thinking movement. Informal Log Newsl. 1983;5(2): 23-24.

10. Paul RW. The critical-thinking movement: a historical perspective. Natl Forum Phi Kappa Phi J. 1985;65(1):2.

11. Tsui L. Fostering critical thinking through effective pedagogy: evidence from four institutional case studies. J High Educ. 2002;73(6):740-763.

12. Whiffin CJ, Hasselder A. Making the link between critical appraisal, thinking and analysis. $\mathrm{Br} \mathrm{J}$ Nurs.
2013;22(14):831-835.

13. Bloom BS, Engelhart MD, Furst EJ, Hill WH, Krathwohl DR. Taxonomy of educational objectives: the classification of education goals: handbook I: cognitive domain. New York, USA: David McKay; 1956.

14. Brookfield SD. Teaching for critical thinking: tools and techniques to help students question their assumptions. San Francisco, USA: Jossey-Bass; 2012.

15. Stacey JD, Granville S. Entering the conversation: reaction papers in advanced academic literacy. Teach High Educ. 2009;14(3):327-339.

16. Badley G. Academic writing as shaping and re-shaping. Teach High Educ. 2009;14(2):209-219.

17. Cowen VS, Kaufman D, Schoenherr L. A review of creative and expressive writing as a pedagogical tool in medical education. Med Educ. 2016;50(3):311-319.

18. Stevens CJ, D’Angelo B, Rennell N, Muzyka D, Pannabecker V, Maid B. Implementing a writing course in an online RN-BSN program. Nurse Educ. 2014;39(1): 17-21.

19. Fankhauser SC, Lijek RS. Incorporating primary scientific literature in middle and high school education. J Microbiol Biol Educ. 2016;17(1):120-124.

20. Peshkin A. The goodness of qualitative research. Educ Res. 1993;22(2):23-29.

21. Henriksen K, Battles JB, Keyes MA, Grady ML. Advances in patient safety: new directions and alternative approaches: vol. 3, performance and tools. Rockville, USA: Agency for Healthcare Research and Quality; 2008.

22. Mun MS. An analysis of narratives to identify critical thinking contexts in psychiatric clinical practice. Int J Nurs Pract. 2010;16(1):75-80.

23. Vachon B, Durand MJ, LeBlanc J. Using reflective learning to improve the impact of continuing education in the context of work rehabilitation. Adv Health Sci Educ Theory Pract. 2010;15(3):329-348.

24. Rashid RA, Hashim RA. The relationship between critical 
thinking and language proficiency of Malaysian undergraduates. Paper presented at: the EDU-COM 2008 International Conference: Sustainability in Higher Education: Directions for Change; November 19-21, 2008; Perth, Western Australia.

25. Mafakheri Laleh M, Mohammadimehr M, Zargar Balaye Jame S. Designing a model for critical thinking development in AJA University of Medical Sciences. J Adv Med Educ Prof. 2016;4(4):179-187.

26. Nicholls S. Beyond expressive writing: evolving models of developmental creative writing. J Health Psychol. 2009; 14(2):171-180.

27. Lordly D, Maclellan D, Gingras J, Brady J. A team-based approach to qualitative inquiry: the collaborative retreat. Can J Diet Pract Res. 2012;73(2):91-97.

28. Leyva-González FA, Cacho-Salazar JM, DegolladoBardales L, et al. Critical reading of reports of edu- cational research in teachers of IMSS: multicenter study. Rev Invest Clin 201 1;63(4):412-422.

29. Antoniou M, Moriarty J. What can academic writers learn from creative writers?: developing guidance and support for lecturers in higher education. Teach High Educ. 2008;13(2):157-167.

30. Murau AM. Shared writing: students' perceptions and attitudes of peer review. Work Pap Educ Linguist. 1993;9(2):71-79.

31. Morss K, Murray R. Researching academic writing within a structured programme: insights and outcomes. Stud High Educ. 2001;26(1):35-52.

32. Domènech AM, Márquez C. Promoting students' critical thinking through the design of scientific researches related to a SSI: the case of $\mathrm{ADHD}$. Paper presented at: ESERA Conference Proceeding; September 2-7, 2013; Nicosia, Cyprus. 